\title{
APPLICATION OF FUZZY AHP AND TOPSIS APPROACH FOR MULTI-OBJECTIVE Scheduling Problems in Robotic Flexible Assembly Cells
}

\section{ABD, K.; ABHARY, K. \& MARIAN, R.}

Abstract: This study describes the application of the developed approach to the scheduling of the Robotic Flexible Assembly Cells (RFACs). The present study is a continuation of the paper titled "development of fuzzy AHP and TOPSIS approach for multi-objective scheduling problems in robotic flexible assembly cells". In this paper, a realistic case study of RFACs is presented to examined and verified the developed approach via implement three phases: problem description; application of FAHPFTOPSIS; and analysis of the results. The analysis showed the stability of the results for FAHP-FTOPSIS and also verified the robustness and the appropriateness of the proposed approach. This study also demonstrated that the proposed approach can be successfully used in the multi-objective optimisation of dynamic scheduling in RFAC.

Key words: Fuzzy AHP, Fuzzy TOPSIS, Scheduling, Robotics, Assembly cells
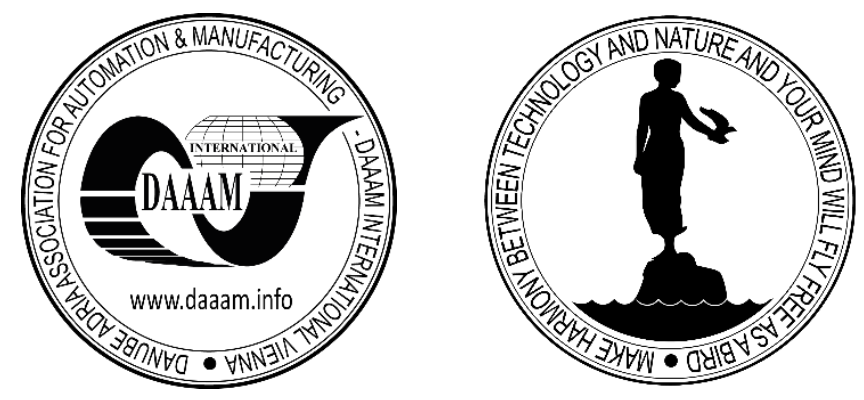

Authors' data: Abd, K[halid]; Abhary, K[azem] \& Marian, R[omeo], University of South Australia, 10 Stuart Road, 5082 Prospect, Australia University of Technology, Baghdad-Iraq, khalid.abd@mymail.unisa.edu.au

This Publication has to be referred as: Abd, K[halid]; Abhary, K[azem] \& Marian, R[omeo] (2017). Application of Fuzzy AHP and TOPSIS Approach for Multiobjective Scheduling Problems in Robotic Flexible Assembly Cells, Chapter 21 in DAAAM International Scientific Book 2017, pp.279-290, B. Katalinic (Ed.), Published by DAAAM International, ISBN 978-3-902734-12-9, ISSN 1726-9687, Vienna, Austria

DOI: $10.2507 /$ daaam.scibook.2017.21 
Abd, K.; Abhary, K. \& Marian, R.: Application of Fuzzy AHP and TOPSIS Approa...

\section{Introduction}

Robotic flexible assembly cells (RFACs) are highly modern systems, structured with industrial robot(s), assembly stations and an automated material handling system, all monitored by computer numerical control $[1,2]$. RFACs are capable of assembling a large variety of products in small to medium batch sizes [3]. The design of RFACs with multi-robots has two key advantages for industrial companies [4-7]. The first advantage is the assembly process needs robots with different characteristics such as end effectors, payload, repeatability, degrees of freedom and accuracy. The second advantage is employing end effectors as fixtures to allow reduction of complex orienting, because the assembly processes of products could require more than one direction of part insertion. With these advantages, employing multi-robots in the assembly cells obviously allows for increasing flexibility and reconfiguration capacity [8]. Nevertheless, the main problem of the RFACs is that more than one robot operating simultaneously in the same workplace needs a complex scheduling and control system to prevent collisions between them [9-11].

Recently, an intelligent approach for scheduling RFACs in a dynamic situation was developed [12]. In this approach, the simulation modelling was integrated with Taguchi optimisation method to study the influence of the scheduling factors on the performance of RFACs. Although the proposed approach is designed to deal with dynamic scheduling in RFACs, it is restricted to solving single-objective optimisation problems.

Therefore, the aim of this paper is to demonstrate the application of the proposed approach to a comprehensive decision problem for multi-objective optimisation of dynamic scheduling problems in RFACs. In order to achieve the stated aim, the following two steps have to be performed sequentially: Implement the proposed approach using fuzzy AHP-fuzzy TOPSIS (FAHP-FTOPSIS). Perform a sensitivity analysis and confirmation test to verify and validate the results obtained.

\section{Case Study}

The objective of this case study is to examine the robustness of the approach presented in previous paper. Three independent objective functions, makespan $\left(C_{\max }\right)$, total tardiness $(T D)$ and number of tardy jobs $\left(N_{T}\right)$ are considered. Tables 1 showed the three objective functions with their signal-to-noise $(\mathrm{S} / \mathrm{N})$ ratios. From these results, for single-objective scheduling, it can be seen that the optimum combination of scheduling factors is the one having the smallest objective function value (the highest $\mathrm{S} / \mathrm{N}$ ratio). Nevertheless, for multi-objective scheduling, it can be concluded that the optimum combination of scheduling factors is not as straightforward as that of singleobjective scheduling, because a higher $\mathrm{S} / \mathrm{N}$ ratio for one objective response may correspond to a lower $\mathrm{S} / \mathrm{N}$ ratio for another objective response. These results reveal that the optimum combination of scheduling factors is multi-criteria decision-making (MCDM) problem. 


\begin{tabular}{|c|c|c|c|c|c|c|c|c|c|}
\hline Alternatives & $\mathbf{C}_{\max }$ & $\mathbf{S} / \mathbf{N}$ & $\mu_{\text {Cmax }}$ & TD & $\mathbf{S} / \mathbf{N}$ & $\mu_{\mathrm{TD}}$ & $\mathbf{N}_{\text {TD }}$ & $\mathbf{S} / \mathbf{N}$ & $\mu_{\mathrm{NTD}}$ \\
\hline $\mathrm{A}_{1}\left(S R_{I} D R_{1} U_{I} K_{I}\right)$ & 38499 & -91.71 & 0.32 & 10070 & -80.061 & 0.35 & 4 & -12.041 & 0.71 \\
\hline $\mathrm{A}_{2}\left(S R_{1} D R_{2} U_{2} K_{2}\right)$ & 34736 & -90.82 & 0.67 & 19124 & -85.632 & 0.21 & 12 & -21.584 & 0.25 \\
\hline $\mathrm{A}_{3}\left(S R_{1} D R_{3} U_{3} K_{3}\right)$ & 31571 & -89.99 & 1.00 & 50161 & -94.007 & 0.00 & 22 & -26.848 & 0.00 \\
\hline $\mathrm{A}_{4}\left(S R_{2} D R_{1} U_{2} K_{3}\right)$ & 35387 & -90.98 & 0.61 & 28904 & -89.219 & 0.12 & 18 & -25.105 & 0.08 \\
\hline$A_{5}\left(S R_{2} D R_{2} U_{3} K_{I}\right)$ & 32488 & -90.23 & 0.90 & 5666.0 & -75.066 & 0.48 & 2 & -6.021 & 1.00 \\
\hline $\mathrm{A}_{6}\left(S R_{2} D R_{3} U_{1} K_{2}\right)$ & 42356 & -92.54 & 0.00 & 9909.0 & -79.921 & 0.36 & 7 & -16.902 & 0.48 \\
\hline$A_{7}\left(S R_{3} D R_{1} U_{3} K_{2}\right)$ & 33003 & -90.37 & 0.85 & 2994.0 & -69.525 & 0.62 & 6 & -15.563 & 0.54 \\
\hline$A_{8}\left(S R_{3} D R_{2} U_{1} K_{3}\right)$ & 39999 & -92.04 & 0.19 & 31792 & -90.046 & 0.10 & 19 & -25.575 & 0.06 \\
\hline $\mathrm{A}_{9}\left(S R_{3} D R_{3} U_{2} K_{1}\right)$ & 36310 & -91.20 & 0.52 & 542.00 & -54.680 & 1.00 & 2 & -6.021 & 1.00 \\
\hline
\end{tabular}

Tab. 1. Simulation results with their normalisations

To simplify the complexity of the MCDM problem, it can be described as a hierarchical structure, as shown in Figure 1. This hierarchy contains three main elements: overall goal, criteria and alternatives.

Overall goal: the main goal is to solve the multi-criteria decision-making problem for optimisation of dynamic scheduling problems in RFAC.

Criteria: The criteria represent the objective functions to fulfil the overall goal. Three objective functions are considered in this problem. These objectives are classified into two types: time-based and due date-based objectives. The makespan $\left(C_{\max }\right)$, is in the first category while total tardiness $(T D)$ and the number of tardy jobs $\left(N_{T}\right)$ fall into the second category.

Alternatives: The decision alternatives represent the simulation experiments (feasible solutions) with respect to the multi-objective functions. These experiments are conducted under different combinations of scheduling factors: sequencing rule $(S R)$, dispatching rule $(D R)$, cell utilisation $(\mathrm{U})$ and due date tightness $(\mathrm{K})$,

After the MCDM problem is constructed as a hierarchical structure, a decision table of the alternatives with respect to the conflicting objectives is built. In the decision table, the $\mathrm{S} / \mathrm{N}$ ratios for the three objective functions, makespan $\left(C_{\max }\right)$, total tardiness (TD) and number of tardy jobs $\left(N_{T}\right)$ must be within the same range. In this case study, the value ranges of the three objectives are all different.

To avoid the different ranges, the values of the $\mathrm{S} / \mathrm{N}$ ratio must be normalised. Since the three objectives are the 'smaller the better' type, the normalisation is determined using Equation (1). The normalisation values are between 0 and 1;0 means the least desirable value while 1 denotes the best value. The simulation results of the three objective functions with their normalisations are shown in Table 1. 
Abd, K.; Abhary, K. \& Marian, R.: Application of Fuzzy AHP and TOPSIS Approa...

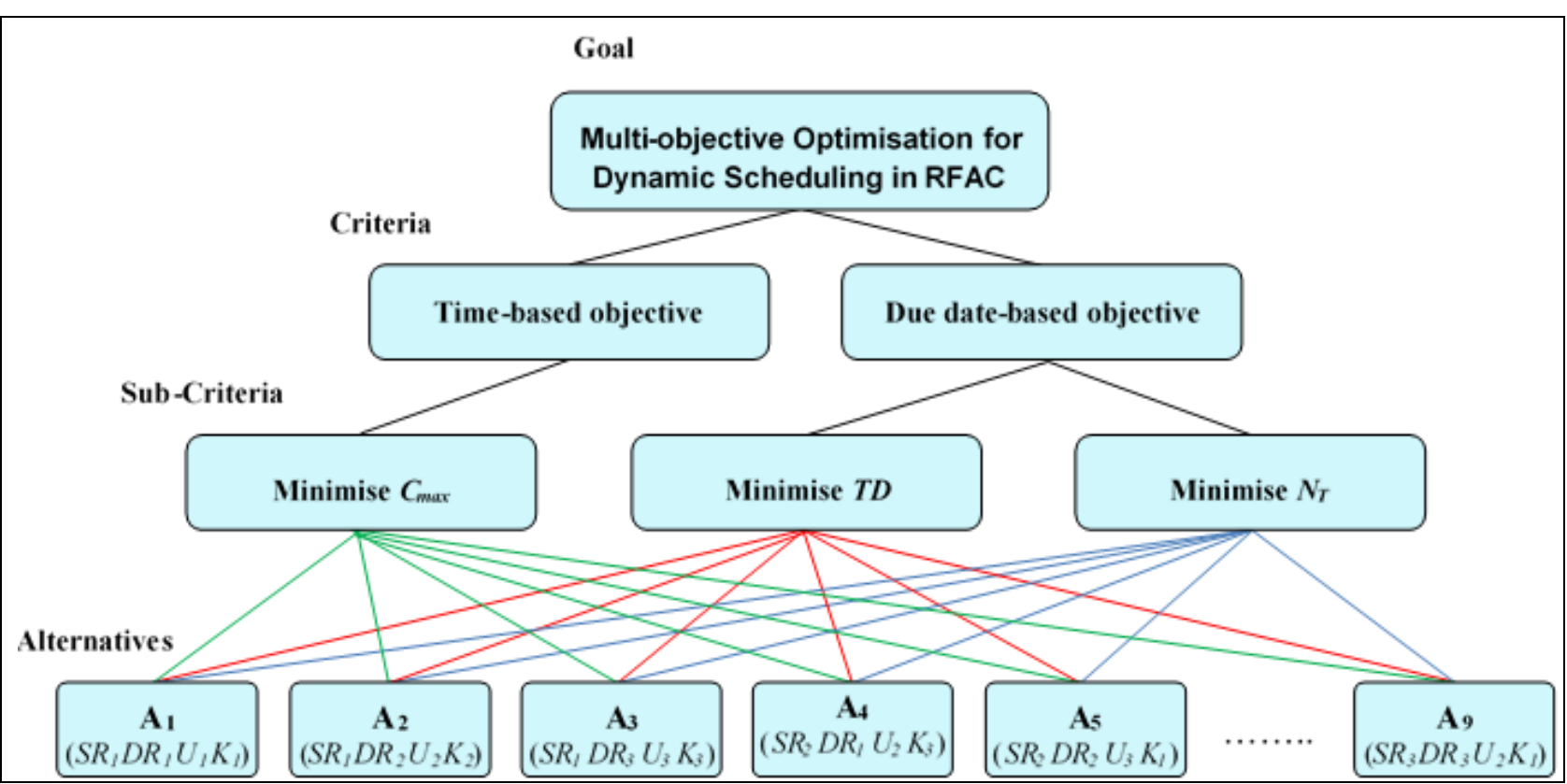

Fig. 1. The decision hierarchy

\section{Application Using FAHP-FTOPSIS}

In this section, the FAHP is applied to determine the weights of the multiple evaluation criteria to be used in the evaluation process, and the FTOPSIS is applied for evaluation of each alternative scheduling combination based on their overall performance in order to make a final decision.

\subsection{Application of FAHP in determining weights of criteria}

In Fuzzy Analytic Hierarchy Process (FAHP), the fuzzy comparison matrix is created by experts who have experience relevant to the related decision area. The experts decide how much one criterion dominates another. Hence, the experts are given the task of forming an individual pairwise comparison matrix by using triangular fuzzy number (TFN). In this research, TFN and the reciprocal scales are defined with the corresponding membership functions as shown in Figure 2 and Table 2 respectively. TFNs are used to overcome shortcomings of the nine-point scale in the traditional AHP. Table 3 presents the aggregate fuzzy comparison matrix with respect to the overall objective.

\begin{tabular}{llll}
\hline Linguistic scale for importance & Linguistic term & $\begin{array}{l}\text { Triangular fuzzy } \\
\text { scale }\end{array}$ & $\begin{array}{l}\text { Triangular fuzzy } \\
\text { reciprocal scale }\end{array}$ \\
\hline Just Equal & & $(1,1,1)$ & $(1,1,1)$ \\
\hline Equal importance & E & $(1,1,3)$ & $(1 / 3,1,1)$ \\
\hline Moderate & M & $(1,3,5)$ & $(1 / 5,1 / 3,1)$ \\
\hline Fairly strong & FS & $(3,5,7)$ & $(1 / 7,1 / 5,1 / 3)$ \\
\hline Very strong & VS & $(5,7,9)$ & $(1 / 9,1 / 7,1 / 5)$ \\
\hline Extremely preferred & EP & $(7,9,9)$ & $(1 / 9,1 / 9,1 / 9)$ \\
\hline
\end{tabular}

Tab. 2. Fuzzy evaluation scale for the weights 


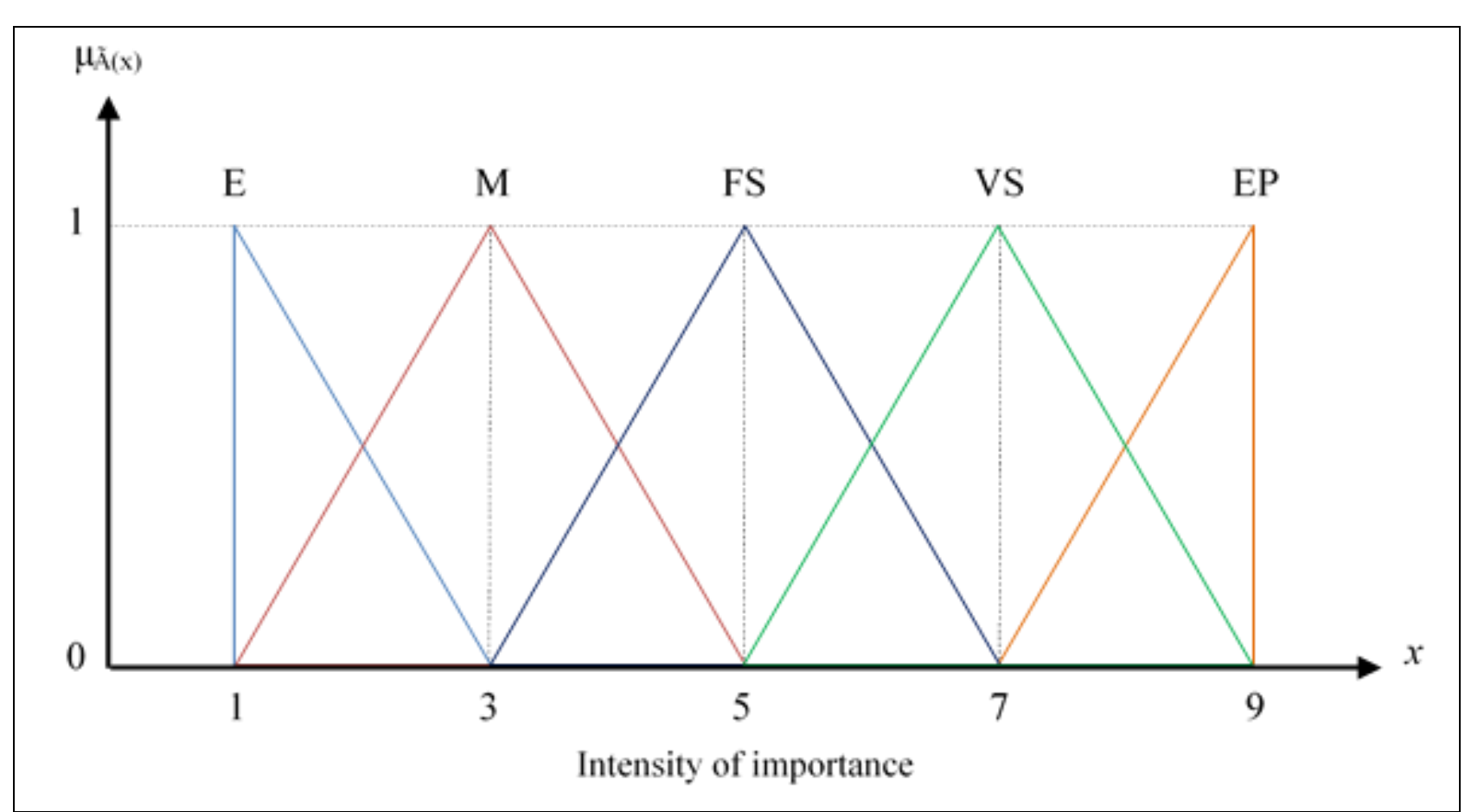

Fig. 2. Linguistic variables for the importance weight of each criterion

\begin{tabular}{llll}
\hline & Makespan $\left(\mathbf{C}_{\mathbf{1}}\right)$ & Total tardiness $\left(\mathbf{C}_{\mathbf{2}}\right)$ & Number of tardy jobs $\left(\mathbf{C}_{\mathbf{3}}\right)$ \\
\hline $\mathbf{C}_{\mathbf{1}}$ & $(1,1,1)$ & $(1,3,5)$ & $(1,3,5)$ \\
\hline $\mathbf{C}_{\mathbf{2}}$ & $(1 / 5,1 / 3,1)$ & $(1,1,1)$ & $(1,1,3)$ \\
\hline $\mathbf{C}_{\mathbf{3}}$ & $(1 / 5,1 / 3,1)$ & $(1 / 3,1,1)$ & $(1,1,1)$ \\
\hline
\end{tabular}

Tab. 3. The fuzzy comparison matrix of criteria

After the fuzzy comparison matrix is constructed, the weight of each criterion can be calculated as follows: Firstly, the values of the fuzzy synthetic extent of the three criteria are calculated as below by using Equation (5):

$\mathrm{S} 1=(3.00,7.00,11.00) \times(19,11.666,6.733)-1=(0.158,0.600,1.634)$

$\mathrm{S} 2=(2.20,2.33,5.00) \times(19,11.666,6.733)-1=(0.116,0.200,0.743)$

$\mathrm{S} 3=(1.53,2.33,3.00) \times(19,11.666,6.733)-1=(0.081,0.200,0.446)$

Secondly, the degrees of possibility of $\mathrm{Si}$ over $\mathrm{Sj}(\mathrm{i} \neq \mathrm{j})$ are calculated by Equation (9).

$\mathrm{V}\left(\mathrm{S}_{1} \geq \mathrm{S}_{2}\right)=1.00$,

$\mathrm{V}\left(\mathrm{S}_{1} \geq \mathrm{S}_{3}\right)=1.00$,

$V\left(S_{2} \geq S_{1}\right)=\frac{(0.158-0.743)}{(0.200-0.743)-(0.600-0.158)}=0.59$,

$\mathrm{V}\left(\mathrm{S}_{2} \geq \mathrm{S}_{3}\right)=1.00$

$V\left(S_{3} \geq S_{1}\right)=\frac{(0.158-0.446)}{(0.200-0.446)-(0.600-0.158)}=0.42$, 
Abd, K.; Abhary, K. \& Marian, R.: Application of Fuzzy AHP and TOPSIS Approa...

$\mathrm{V}\left(\mathrm{S}_{3} \geq \mathrm{S}_{2}\right)=1.00$

Thirdly, the minimum degree of possibility is determined using Equation (12) as follows:

$m\left(\mathrm{C}_{1}\right)=\min \mathrm{V}\left(\mathrm{S}_{i} \geq \mathrm{S}_{k}\right)=\min (1.00,1.00)=1.00$

$m\left(\mathrm{C}_{2}\right)=\min \mathrm{V}\left(\mathrm{S}_{i} \geq \mathrm{S}_{k}\right)=\min (0.59,1.00)=0.59$

$m\left(\mathrm{C}_{3}\right)=\min \mathrm{V}\left(\mathrm{S}_{i} \geq \mathrm{S}_{k}\right)=\min (0.42,1.00)=0.42$

Therefore, the weight vector is given by: $\mathrm{Wc}=(1.00,0.59,0.42) \mathrm{T}$. Finally, after normalising Wc, the normalised weight vectors of each of the three criteria can be determined as $\mathrm{W}=(0.497,0.295,0.208) \mathrm{T}$. The makespan $(\mathrm{C} 1)$ is determined as the most important criterion in the combinations of scheduling factors, followed by total tardiness (C2); the number of tardy jobs (C3) appears to be less significant. After the weights of each criterion are calculated, the last stage in FAHP is to identify the consistency of the linguistic values in the fuzzy comparison matrix.

In this sudy, the consistency ratio (CR) is calculated. The results obtained from the calculations based on the fuzzy comparison matrix are presented in Table 4. As can be seen from Table 4, the consistency ratio (CR) is less than 0.10 . Thus, the weights are consistent and they are able to be used in the evaluation process.

\begin{tabular}{llllll}
\hline Criteria & Weights (w) & $\boldsymbol{\lambda}_{\max }$ & $\boldsymbol{C I}$ & $\boldsymbol{R I}$ & $\boldsymbol{C R}$ \\
\hline $\mathbf{C}_{\mathbf{1}}$ & 0.497 & 3.0921 & 0.0145 & 0.58 & 0.0251 \\
$\mathbf{C}_{\mathbf{2}}$ & 0.295 & & & & \\
$\mathbf{C}_{\mathbf{3}}$ & 0.208 & & & & \\
\hline
\end{tabular}

Tab. 4. Results obtained from FAHP approach

\subsection{Application of FTOPSIS in ranking of alternatives}

In FTOPSIS, six stages are required for evaluating and ranking the alternatives.

Stage 1: Establish the fuzzy decision matrix by evaluating alternatives under each of the criteria using linguistic variables. The membership functions of these linguistic variables are shown in Figure 3. In this study, nine alternatives (scheduling factor combinations) must be evaluated with respect to each criterion, as shown in Table 1. The fuzzy decision matrix of the elements in is demonstrated in Table 4. 


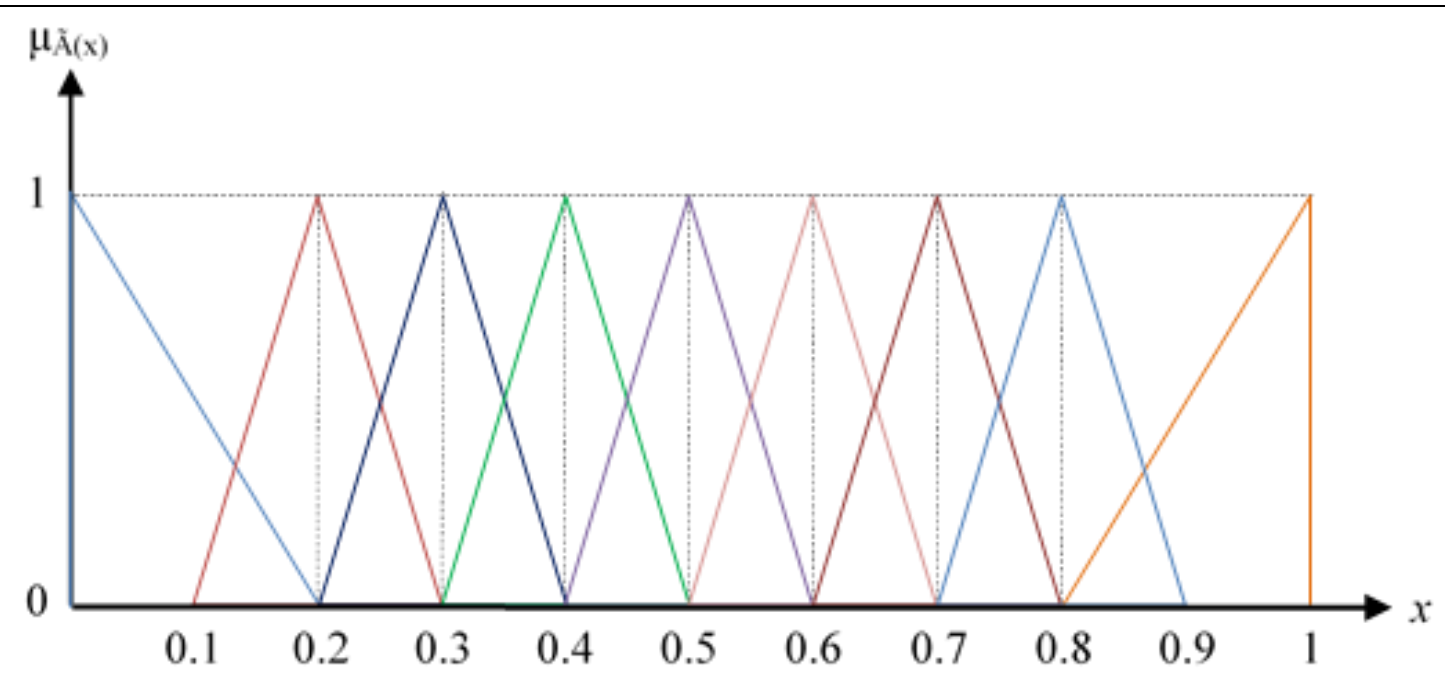

Fig. 3. Membership functions of linguistic variable set

Stage 2: Normalise the fuzzy decision matrix. Since the ranges of all the values belong to the closed interval $[0,1]$, there is no need for normalisation.

Stage 3: Obtain a weighted decision matrix. This matrix can be established using the Equation (13) and the criteria weights calculated by fuzzy AHP. The weighted decision matrix is presented in Table 5.

Stage 4: Determine the fuzzy positive ideal solution $\left(F P I S, A^{+}\right)$and the fuzzy negative ideal solution (NPIS, $A^{-}$) using Equations 23 and 24. In this problem, $\mathrm{C}_{1}, \mathrm{C}_{2}, \mathrm{C}_{3}$ are considered as benefit criteria, so $\tilde{v}_{1}^{+}=(1,1,1)$ and $\tilde{v}_{1}^{-}=(0,0,0)$, as shown in Table 5 .

Stage 5: Calculate the distance of each alternative $\left(d_{i}^{+}, d_{i}^{-}\right)$from FPIS and FNIS using Equations 27 and 28, as shown below as an example illustrating this calculation.

Stage 6: Calculate the closeness coefficient of each alternative using Equation 29. The final results obtained by the FTOPSIS are summarised in Table 6 .

\begin{tabular}{lccc}
\hline Alternatives & $\mathbf{C}_{\mathbf{1}}$ & $\mathbf{C}_{\mathbf{2}}$ & $\mathbf{C}_{\mathbf{3}}$ \\
\hline $\mathbf{A}_{\mathbf{1}}\left(S R_{1} D R_{1} U_{l} K_{l}\right)$ & $(0.2,0.3,0.4)$ & $(0.3,0.4,0.5)$ & $(0.6,0.7,0.8)$ \\
\hline $\mathbf{A}_{\mathbf{2}}\left(S R_{1} D R_{2} U_{2} K_{2}\right)$ & $(0.6,0.7,0.8)$ & $(0.1,0.2,0.3)$ & $(0.2,0.3,0.4)$ \\
\hline $\mathbf{A}_{\mathbf{3}}\left(S R_{1} D R_{3} U_{3} K_{3}\right)$ & $(0.8,1.0,1.0)$ & $(0.0,0.0,0.2)$ & $(0.0,0.0,0.2)$ \\
\hline $\mathbf{A}_{\mathbf{4}}\left(S R_{2} D R_{1} U_{2} K_{3}\right)$ & $(0.5,0.6,0.7)$ & $(0.0,0.0,0.2)$ & $(0.0,0.0,0.2)$ \\
\hline $\mathbf{A}_{\mathbf{5}}\left(S R_{2} D R_{2} U_{3} K_{l}\right)$ & $(0.8,1.0,1.0)$ & $(0.4,0.5,0.6)$ & $(0.8,1.0,1.0)$ \\
\hline $\mathbf{A}_{\mathbf{6}}\left(S R_{2} D R_{3} U_{1} K_{2}\right)$ & $(0.0,0.0,0.2)$ & $(0.3,0.4,0.5)$ & $(0.4,0.5,0.6)$ \\
\hline $\mathbf{A}_{\mathbf{7}}\left(S R_{3} D R_{1} U_{3} K_{2}\right)$ & $(0.7,0.8,0.9)$ & $(0.5,0.6,0.7)$ & $(0.4,0.5,0.6)$ \\
\hline $\mathbf{A}_{\mathbf{8}}\left(S R_{3} D R_{2} U_{1} K_{3}\right)$ & $(0.1,0.2,0.3)$ & $(0.0,0.0,0.2)$ & $(0.0,0.0,0.2)$ \\
\hline $\mathbf{A}_{\mathbf{9}}\left(S R_{3} D R_{3} U_{2} K_{l}\right)$ & $(0.4,0.5,0.6)$ & $(0.8,1.0,1.0)$ & $(0.8,1.0,1.0)$ \\
\hline Weight & 0.497 & 0.295 & 0.208 \\
\hline
\end{tabular}

Tab. 4. Fuzzy decision matrix for nine alternatives with three criteria 
Abd, K.; Abhary, K. \& Marian, R.: Application of Fuzzy AHP and TOPSIS Approa...

\begin{tabular}{cccc}
\hline Alternatives & $\mathbf{C}_{\mathbf{1}}$ & $\mathbf{C}_{\mathbf{2}}$ & $\mathbf{C}_{\mathbf{3}}$ \\
\hline $\mathbf{A}_{\mathbf{1}}$ & $(0.099,0.149,0.198)$ & $(0.088,0.118,0.147)$ & $(0.124,0.145,0.166)$ \\
$\mathbf{A}_{\mathbf{2}}$ & $(0.298,0.347,0.397)$ & $(0.029,0.059,0.088)$ & $(0.041,0.062,0.083)$ \\
\hline $\mathbf{A}_{\mathbf{3}}$ & $(0.397,0.497,0.497)$ & $(0.000,0.000,0.059)$ & $(0.000,0.000,0.041)$ \\
$\mathbf{A}_{\mathbf{4}}$ & $(0.248,0.298,0.347)$ & $(0.000,0.000,0.059)$ & $(0.000,0.000,0.041)$ \\
\hline $\mathbf{A}_{\mathbf{5}}$ & $(0.397,0.497,0.497)$ & $(0.118,0.147,0.177)$ & $(0.166,0.208,0.208)$ \\
\hline $\mathbf{A}_{\mathbf{6}}$ & $(0.000,0.000,0.099)$ & $(0.088,0.118,0.147)$ & $(0.083,0.104,0.124)$ \\
$\mathbf{A}_{\mathbf{7}}$ & $(0.347,0.397,0.447)$ & $(0.147,0.177,0.206)$ & $(0.083,0.104,0.124)$ \\
$\mathbf{A}_{\mathbf{8}}$ & $(0.049,0.099,0.149)$ & $(0.000,0.000,0.059)$ & $(0.000,0.000,0.041)$ \\
\hline $\mathbf{A}_{\mathbf{9}}$ & $(0.198,0.248,0.298)$ & $(0.236,0.295,0.295)$ & $(0.166,0.208,0.208)$ \\
\hline $\boldsymbol{A}^{+}$ & $\tilde{v}_{1}^{+}=(1,1,1)$ & & \\
\hline $\boldsymbol{A}^{-}$ & $\tilde{v}_{1}^{-}=(0,0,0)$ & $\tilde{v}_{2}^{+}=(1,1,1)$ & $\tilde{v}_{3}^{+}=(1,1,1)$ \\
\hline
\end{tabular}

Tab. 5. Weighted decisions for alternatives

$$
\begin{aligned}
\boldsymbol{d}_{\mathbf{1}}^{+} & =\sqrt{\frac{1}{3}\left[(1-0.099)^{2}+(1-0.149)^{2}+(1-0.198)^{2}\right]} \\
& +\sqrt{\frac{1}{3}\left[(1-0.088)^{2}+(1-0.118)^{2}+(1-0.147)^{2}\right]} \\
& +\sqrt{\frac{1}{3}\left[(1-0.124)^{2}+(1-0.145)^{2}+(1-0.166)^{2}\right]}=\mathbf{2 . 5 8 9} \\
\boldsymbol{d}_{\mathbf{1}}^{-} & =\sqrt{\frac{1}{3}\left[(0-0.099)^{2}+(0-0.149)^{2}+(0-0.198)^{2}\right]} \\
& +\sqrt{\frac{1}{3}\left[(0-0.088)^{2}+(0-0.118)^{2}+(0-0.147)^{2}\right]} \\
& +\sqrt{\frac{1}{3}\left[(0-0.124)^{2}+(0-0.145)^{2}+(0-0.166)^{2}\right]}=\mathbf{2 . 1 0 2}
\end{aligned}
$$

\begin{tabular}{ccccc}
\hline Alternatives & $\boldsymbol{d}_{\boldsymbol{j}}^{+}$ & $\boldsymbol{d}_{\boldsymbol{j}}^{-}$ & $\boldsymbol{C C}_{\boldsymbol{j}}$ & Rank \\
\hline $\mathbf{A}_{\mathbf{1}}$ & 2.589 & 2.102 & 0.448 & 7 \\
$\mathbf{A}_{\mathbf{2}}$ & 2.532 & 2.323 & 0.478 & 5 \\
$\mathbf{A}_{\mathbf{3}}$ & 2.505 & 2.453 & 0.495 & 3 \\
$\mathbf{A}_{\mathbf{4}}$ & 2.670 & 2.287 & 0.461 & 6 \\
\hline $\mathbf{A}_{\mathbf{5}}$ & 2.197 & 2.402 & 0.522 & 1 \\
$\mathbf{A}_{\mathbf{6}}$ & 2.746 & 2.018 & 0.424 & 8 \\
\hline $\mathbf{A}_{\mathbf{7}}$ & 2.323 & 2.360 & 0.504 & 2 \\
\hline $\mathbf{A}_{\mathbf{8}}$ & 2.869 & 2.094 & 0.422 & 9 \\
\hline $\mathbf{A}_{\mathbf{9}}$ & 2.284 & 2.188 & 0.489 & 4 \\
\hline
\end{tabular}

Tab. 6. FTOPSIS results 


\section{Analysis of Results and Discussion}

Based on FAHP-FTOPSIS results, the alternative $A_{5}\left(S R_{2} D R_{2} U_{3} K_{l}\right)$ is closest to the fuzzy positive ideal solution (FPIS) with a value of 2.197, and the alternative $A_{8}$ $\left(S R_{3} D R_{2} U_{1} K_{3}\right)$ is located farthest from the fuzzy negative ideal solution (FNIS) with a value of 2.869. The alternative $A_{3}\left(S R_{l} D R_{3} U_{3} K_{3}\right)$ is located farthest from the FNIS with a value of 2.453 , and the alternative $A_{6}\left(S R_{2} D R_{3} U_{1} K_{2}\right)$ is closest to the FNIS with a value of 2.018 .

According to the results in, it can be seen that the alternative $A_{5}\left(S R_{2} D R_{2} U_{3} K_{l}\right)$ is the optimal combination of scheduling factors, with a relative closeness coefficient $\left(C C_{j}\right)$ value of 0.522 . The alternative $A_{7}\left(S R_{3} D R_{1} U_{3} K_{2}\right)$ has a $C C_{j}$ value of 0.504 and is ranked second in these results. The alternative $A_{3}\left(S R_{1} D R_{3} U_{3} K_{3}\right)$ is ranked third with a $C C_{j}$ value of 0.495 . The worst alternative is $A_{8}\left(S R_{3} D R_{2} U_{1} K_{3}\right)$ with a $C C_{j}$ value of 0.422 . Therefore, the descending order of the final ranking using FAHP-FTOPSIS is: $A_{5}>A_{7}>A_{3}>A_{9}>A_{2}>A_{4}>A_{1}>A_{6}>A_{8}$.

To conduct the sensitivity analysis for the results obtained by FAHP-FTOPSIS, change the weight of each individual criterion, and keep the summation total of all criteria weights equal to one. The decision-maker can assume different scenarios. Scenario 0 shows the original weights' values as calculated by FAHP, whereas the other scenarios (Scenario 1, Scenario $2 \ldots$ Scenario $n$ ) all show different weights values. For example, the total weight of the makespan $\left(\mathrm{C}_{1}\right)$, total tardiness $\left(\mathrm{C}_{2}\right)$ and number of tardy jobs $\left(\mathrm{C}_{3}\right)$ is equal to one $(0.497+0.295+0.208=1)$; these original weights represent Scenario 0.

The other scenarios can be established for example by increasing $C_{1}$ to 0.55 , increasing $C_{2}$ to 0.30 and decreasing $C_{3}$ to 0.15 . Table 7 summarises the numerical results of three different scenarios.

\begin{tabular}{lcccc}
\hline Criteria & Scenario 0 & Scenario 1 & Scenario 2 & Scenario 3 \\
\hline Makespan $\left(\mathrm{C}_{1}\right)$ & 0.497 & 0.55 & 0.50 & 0.45 \\
Total tardiness $\left(\mathrm{C}_{2}\right)$ & 0.295 & 0.30 & 0.20 & 0.35 \\
Number of tardy jobs $\left(\mathrm{C}_{3}\right)$ & 0.208 & 0.15 & 0.30 & 0.20 \\
\hline
\end{tabular}

Tab. 7. the weight of individual criterion

\begin{tabular}{lcccc}
\hline \multirow{2}{*}{ Alternatives } & \multicolumn{4}{c}{ Relative closeness coefficient $(\mathrm{CC} \mathbf{j})$} \\
\cline { 2 - 5 } & Scenario 0 & Scenario 1 & Scenario 2 & Scenario 3 \\
\hline $\mathrm{A}_{1}\left(S R_{l} D R_{l} U_{l} K_{l}\right)$ & 0.448 & 0.450 & 0.448 & 0.447 \\
$\mathrm{~A}_{2}\left(S R_{l} D R_{2} U_{2} K_{2}\right)$ & 0.478 & 0.485 & 0.479 & 0.473 \\
$\mathrm{~A}_{3}\left(S R_{l} D R_{3} U_{3} K_{3}\right)$ & 0.495 & 0.505 & 0.495 & 0.486
\end{tabular}


Abd, K.; Abhary, K. \& Marian, R.: Application of Fuzzy AHP and TOPSIS Approa...

$\begin{array}{lllll}\mathrm{A}_{4}\left(S R_{2} D R_{1} U_{2} K_{3}\right) & 0.461 & 0.468 & 0.461 & 0.456 \\ \mathrm{~A}_{5}\left(S R_{2} D R_{2} U_{3} K_{l}\right) & 0.522 & 0.529 & 0.525 & 0.515 \\ \mathrm{~A}_{6}\left(S R_{2} D R_{3} U_{l} K_{2}\right) & 0.424 & 0.423 & 0.422 & 0.424 \\ \mathrm{~A}_{7}\left(S R_{3} D R_{1} U_{3} K_{2}\right) & 0.504 & 0.511 & 0.501 & 0.499 \\ \mathrm{~A}_{8}\left(S R_{3} D R_{2} U_{l} K_{3}\right) & 0.422 & 0.424 & 0.421 & 0.420 \\ \mathrm{~A}_{9}\left(S R_{3} D R_{3} U_{2} K_{l}\right) & 0.489 & 0.492 & 0.486 & 0.489\end{array}$

Tab. 8. Sensitivity analysis for FAHP-FTOPSIS based on first procedure

As shown in Figure 4, the final ranking in Scenario 0 is nearly the same as for all the other scenarios (Scenario 1, Scenario 2 and Scenario 3). For example, A5, A7, $\mathrm{A} 2$, A4 and A1 have the same rankings in all scenarios. In this example, even though the weights of the criteria $(\mathrm{C} 1, \mathrm{C} 2$ and $\mathrm{C} 3)$ are each changed from the original weights, this has only a minor influence on the final ranking.

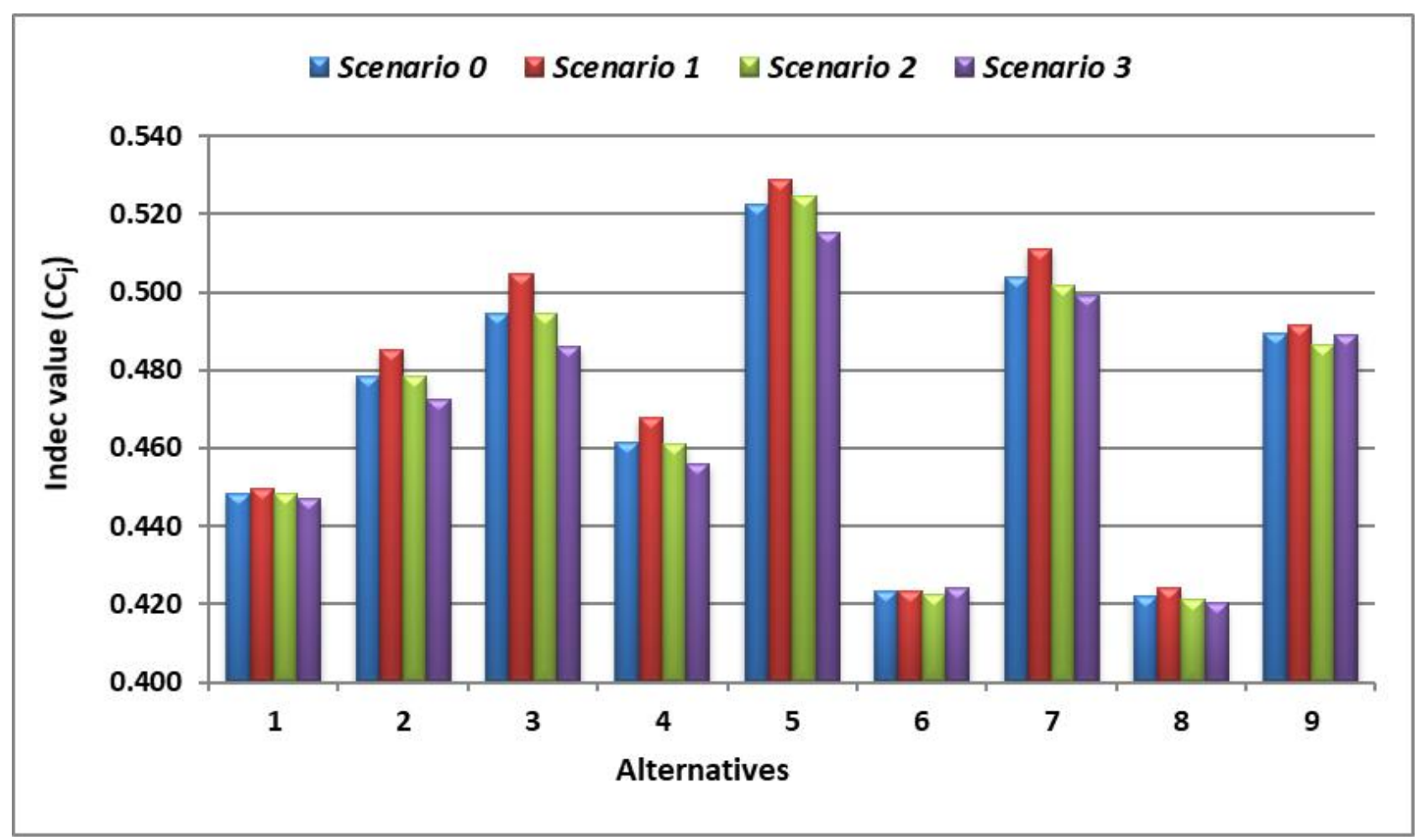

Fig. 4. Sensitivity analysis for FAHP-FTOPSIS

\section{Conclusion}

The research work described in previous paper, development of fuzzy AHP and TOPSIS approach for multi-objective scheduling problems in robotic flexible assembly cells, was devoted to develop a new approach based on FAHP-FTOPSIS for solving optimisation problems.

The objective of this paper, a hypothetical case study was applied to demonstrate the effectiveness of the developed approach that presented in previous paper. In order to achieve the stated objective, the following two steps have to be performed 
sequentially: first; Implement the proposed approach using fuzzy AHP-fuzzy TOPSIS (FAHP-FTOPSIS); and then perform a sensitivity analysis and confirmation test to verify and validate the results obtained.

The results achieved in this paper illustrate that the final ranking in Scenario 0 is relatively less sensitive to the changes in fuzzy rules. Hence, it can be concluded that almost all of the changes in the weight of each criterion do not have significant influence on the final ranking. Thus, the sensitivity analysis reflects the stability of the results in Scenario 0, and demonstrates the robustness of the FAHP - FTOPSIS approach.

A further research can be suggested to continue the current work. This can be done by comparing the obtained results of the proposed FAHP-FTOPSIS with fuzzy decision support system (FDSS) to check the reliability and consistency of the proposed approach. The FDSS can be built using a MATLAB fuzzy logic toolbox.

\section{References}

Marian, R. M. Kargas, A. Luong, L. H. S. \& Abhary, K., 2003 "framework to planning robotic flexible assembly cells," in 32nd International Conference on Computers and Industrial Engineering, Limerick, Ireland, pp. 607- 615.

Manivannan, S., 1993 "Robotic collision avoidance in a flexible assembly cell using a dynamic knowledge base'," IEEE transactions on systems, man, and cybernetics, vol. 23, pp. 766-782.

Mohamed, S. B. Petty, D. J. Harrison, D. K. \& Rigby, R. 2001 "A cell management system to support robotic assembly'," The International Journal of Advanced Manufacturing Technology, vol. 18, pp. 598-604.

Abd, K, Abhary, K \& Marian, R 2013, 'Intelligent model of scheduling RFACs - Part I: methodology and strategy', DAAAM International Scientific Book Vienna: DAAAM International Publishing, pp. 719-736.

Abd, K, Abhary, K \& Marian, R 2013, 'Intelligent model of scheduling RFACs - Part II: application', DAAAM International Scientific Book Vienna: DAAAM International Publishing, pp. 737-750.

Abd, K, Abhary, K \& Marian, R 2012, "Intelligent Modelling of Scheduling Robotic Flexible Assembly Cells Using Fuzzy Logic," in 12th World Scientific and Engineering Academy and Society (WSEAS), International Conference on Robotics, Control and Manufacturing Technology, Rovaniemi, Finland, pp. 202-207.

Abd, K, Abhary, K \& Marian, R 2013, "A Methodology for scheduling Robotic Flexible Assembly Cells Using Fuzzy Logic and Simulation," in Manufacturing Engineering and Engineering Management, London, U.K, pp. 449- 454. 
Abd, K.; Abhary, K. \& Marian, R.: Application of Fuzzy AHP and TOPSIS Approa...

Glibert, P. R. Coupez, D. Peng, Y. M. \& Delchambre, A. 1990 "Scheduling of a multirobot assembly cell," Computer Integrated Manufacturing Systems, vol. 3, pp. 236245.

Abd, K, Abhary, K \& Marian, R 2012 "Efficient Scheduling Rule for Robotic Flexible Assembly Cells Based on Fuzzy Approach," in Procedia CIRP, 45th CIRP Conference on Manufacturing Systems Athens, pp. 483-488.

Abd, K, Abhary, K \& Marian, R 2013, "Intelligent Model of Scheduling RFACs - Part I: Methodology and Strategy," in DAAAM International Scientific Book vol. 12, B. Katalinic and Z. Tekic, Eds., ed Vienna: DAAAM International Publishing, pp. 719736.

Abd, K, Abhary, K \& Marian, R 2013, "Application of a fuzzy-simulation model of scheduling robotic flexible assembly cells," Journal of Computer Science, vol. 9, pp. 1769-1777.

Abd, K, Abhary, K \& Marian, R 2013, 'Development of a fuzzy-simulation model of scheduling robotic flexible assembly cells', Journal of Computer Science, vol. 9, no. 12, pp. 1761-1768. 